\title{
Motivational predictors of change in oral health: an experimental test of self-determination theory
}

\author{
Anne E. Münster Halvari • Hallgeir Halvari
}

Published online: 12 May 2007

(C) Springer Science+Business Media, LLC 2007

Erratum to: Motivation and Emotion, Vol. 30, No. 4, December 2006 DOI: 10.1007/s11031-006-9035-8

In Table 4, the correct correlation between variable 5 (Intervention) and variable 7 (Oral health attitudes and affect) should be .38 , NOT -.38 . This is the same correlation that should also appear in Table 3 between variable 5 and variable 11 , and it is .38 .

The online version of the original article can be found at: http://dx.doi.org/10.1007/s11031-006-9035-8

\footnotetext{
A. E. M. Halvari $(\square)$

Faculty of Odontology, Department of Dental Hygienist

Education, University of Oslo,

Geitmyrsveien 69/71,

0455 Oslo, Norway

e-mail: ahalvari@odont.uio.no

H. Halvari

Faculty of Education in Business Administration,

Buskerud University College,

Kongsberg, Norway
} 